\title{
Comparison of the sensitivity of three methods for the rapid identification of Cryptococcus neoformans
}

\author{
J COHEN
}

From the Departments of Medicine and Bacteriology, Hammersmith Hospital, Royal Postgraduate Medical School, Du Cane Road, London W12 OHS

SUMMARY The sensitivity of three methods for the rapid identification of Cryptococcus neoformans was compared. These were: direct microscopy of india ink preparations, acridine orange staining followed by fluorescence microscopy and detection of cryptococcal capsular polysaccharide antigen by latex agglutination.

The overall limit of detection was $3.5 \pm 5.4 \times 10^{3} \mathrm{CFU} / \mathrm{ml}($ mean $\pm \mathrm{SD}, \mathrm{n}=27)$. When different strains were studied, no single method was consistently superior. False positive results were rare (two of 162 observations, $1.2 \%$ ) but there were eight false negatives (4.9\%), five of which were with acridine orange.

Tests such as these are an invaluable aid in the rapid diagnosis of cryptococcal meningitis but they cannot be relied upon to detect low grade infections.

Cryptococcal meningitis is a life threatening condition which generally presents as an opportunist infection in immunocompromised hosts. ${ }^{1}$ The diagnosis is confirmed by culture of the organism, but because of the urgent need to initiate treatment it is important to attempt to make a presumptive diagnosis by direct examination of the cerebrospinal fluid (CSF).

For many years "negative staining" with india ink has been used for this purpose, but it is positive in only about $60 \%$ of cases of culture-proven infection..$^{2}$ Another method, now widely available, is the latex agglutination test, which detects the presence of the capsular polysaccharide antigen by the agglutination of antibody-coated latex particles. ${ }^{3}$

An alternative approach was suggested by the observation that fluorochromes such as acridine orange could be used to stain the capsular material of $C$ neoformans, producing a bright yellow colour when examined by fluorescence microscopy. ${ }^{4}$

This study was designed to compare the sensitivity of these three methods for the rapid diagnosis of cryptococcal infection.

\section{Material and methods}

ORGANISMS

Three strains of $C$ neoformans of varying capsule

Accepted for publication 22 November 1983 size were used. Strain $\mathrm{H} 22$ was a human CSF isolate (kindly supplied by Dr G Kaminski, Adelaide Childrens Hospital, Australia), H40, a human bone isolate (a gift from Dr D Frey, Royal North Shore Hospital, Sydney, Australia), and H99, from the CSF of a patient with Hodgkin's disease (from Dr JR Perfect, Duke University Medical Center, N Carolina, USA). The identity of each strain was confirmed on the basis of carbohydrate assimilation tests and the characteristic pigmentation of the colonies when grown on niger seed agar. Capsular size was estimated by making fresh subcultures of each strain on Sabouraud's agar for $48 \mathrm{~h}$. India ink preparations were examined and the diameter of the cells measured with a micrometer eyepiece.

The isolates were serotyped by inoculation on CGB agar (canavanine-glycine-bromthymol blue) ${ }^{5}$ and GCA (glycine cycloheximide agar) ${ }^{6}$ and the mating type established by incubating each strain with tester strains of known mating type (B3501 and B3502, both kindly supplied by Dr J Kwon Chung, National Institutes of Health, Bethesda, MA) on three different sporulation agars.'

The organisms were maintained on Sabouraud's agar slants and subcultured $48 \mathrm{~h}$ before each experiment.

PREPARATION OF THE INOCULUM

The organisms were taken up on a loop into sterile normal saline and the optical density adjusted to 1.5 
\pm 0.2 at $540 \mathrm{~nm}$. Serial tenfold dilutions were made, and $50 \mu \mathrm{l}$ aliquots cultured on Sabouraud's agar to determine the viable count of the inoculum. Five $\mathrm{ml}$ volumes of each dilution were centrifuged at $650 \mathrm{~g}$ for $15 \mathrm{~min}$, and $4 \mathrm{ml}$ of the supernatant discarded. The deposit was mixed well and held on ice.

Two blank tubes containing $1 \mathrm{ml}$ of normal saline were prepared. Four test dilutions in the range $1 \times$ $10^{5}$ to $1 \times 18^{1} \mathrm{CFU} / \mathrm{ml}$ plus the two blanks were then coded and examined blind.

\section{TEST PROCEDURES}

Twenty-five microlitres of each sample was mixed with $5 \mu \mathrm{l}$ of india ink and examined for 6 min under a $\times 25$ (sometimes $\times 40$ ) objective.

Next, $90 \mu \mathrm{l}$ of sample was incubated with $10 \mu \mathrm{l}$ of freshly prepared $0.05 \%$ acridine orange (Sigma, Poole, Dorset) at room temperature for $6 \mathrm{~min}$, and then $28 \mu \mathrm{l}$ examined for $6 \mathrm{~min}$ by fluorescence microscopy with a $\times 40$ objective. We used an Olympus $\mathrm{BH} 2$ microscope with an EY455 filter equipped with a quartz halogen light to provide incident light fluorescence.

Finally, each sample was tested using a commercial latex agglutination test (Crypto-Test, MA Bioproducts, Walkersville, MD) following the manufacturers' instructions. Dilutions for this test were made in glycine saline buffer (glycine $7 \cdot 1 \mathrm{~g}, \mathrm{NaCl} 10 \mathrm{~g}, 1 \mathrm{~N}$ $\mathrm{NaOH} 3.5 \mathrm{ml}$, distilled water to 1 litre, plus $0.1 \%$ bovine serum albumin, final $\mathrm{pH} 8 \cdot 2$ ).

\section{CALCULATIONS}

The highest dilution for which a positive result was obtained was used to determine the sensitivity of the test for that strain by reference to the viable count in the original inoculum. False-positives were a positive result on a blank control, or a positive result when at least two higher concentrations were recorded as negative. False negatives were samples in which a clear positive was obtained with the same method at a lower concentration.

\section{Results}

The overall level of sensitivity was $3 \cdot 5 \pm 5 \cdot 4 \times 10^{3}$ colony forming units $(\mathrm{CFU}) / \mathrm{ml}$ (mean $\pm \mathrm{SD}, \mathrm{n}=$ 27). Comparing the three strains, the mean level of detection, by all methods, was: H99: $6.7 \pm 8 \cdot 1 \times$ $10^{3} \mathrm{CFU} / \mathrm{ml} ; \mathrm{H} 22: 3.1 \pm 4.9 \times 10^{3} \mathrm{CFU} / \mathrm{ml} ; \mathrm{H} 40$ : $6.4 \pm 1 \cdot 2 \times 10^{2} \mathrm{CFU} / \mathrm{ml}$.

The sensitivity of the three diagnostic methods was compared by determining the limit of detection of each method for all three strains. For acridine orange, this was $4 \cdot 1 \pm 4 \cdot 2 \times 10^{3} \mathrm{CFU} / \mathrm{ml}$, for india ink, $6.7 \pm 3.8 \times 10^{2} \mathrm{CFU} / \mathrm{ml}$, and for latex agglutination $3 \cdot 2 \pm 4 \cdot 1 \times 10^{2} \mathrm{CFU} / \mathrm{ml}$. However when the three methods were compared for their sensitivity for each strain, india ink proved best for $\mathrm{H} 99$ (at $1 \cdot 1$ $\left.\pm 1.0 \times 10^{3} \mathrm{CFU} / \mathrm{ml}\right)$, latex agglutination for $\mathrm{H} 22$ $\left(1.8 \pm 1.9 \times 10^{2} \mathrm{CFU} / \mathrm{ml}\right)$ and india ink and acridine orange were equally good for $\mathrm{H} 40(5.7 \pm$ $\left.5.4 \times 10^{2} \mathrm{CFU} / \mathrm{ml}\right)$. These results are summarised in the Table.

There were two false-positives in the total of 162 observations $(1.2 \%)$. In one case a single organism was thought to be present by acridine orange examination in one of the blank controls, and in the other a latex agglutination was read as \pm when two higher concentrations were both negative. Eight false negative results were obtained $(4.9 \%)$, five with the acridine orange method, two with india ink and one with latex agglutination.

Both $\mathrm{H} 99$ and $\mathrm{H} 40$ were of $\mathrm{A} / \mathrm{D}$ serotype, while $\mathrm{H} 22$ was $\mathrm{B} / \mathrm{C}$. All three strains were of " $\mathrm{a}$ " mating type. The mean diameter $(n=10)$ of $\mathrm{H} 99$ cells was $5.3 \mu \mathrm{m}$, of $\mathrm{H} 226.3 \mu \mathrm{m}$, and of $\mathrm{H} 406.5 \mu \mathrm{m}$.

\section{Discussion}

There is no doubt that culture of an adequate quantity of CSF is the most sensitive means of diagnosing cryptococcal meningitis. ${ }^{\text {} ~ H o w e v e r ~ t h i s ~ m a y ~ i n v o l v e ~}$ a delay of several days particularly if there are relatively few organisms, and the clinical circumstances often dictate the need for a more rapid diagnosis. The results presented here suggest that both the conventional methods in widespread use (that is, india ink and latex agglutination) are of comparable sensitivity. Extensive experience with auramine staining of Mycobacterium tuberculosis suggested

Summary of the sensitivity (in CFU/ml) of three methods for the detection of three strains of $C$ neoformans

\begin{tabular}{|c|c|c|c|c|}
\hline & $H 99$ & $H 22$ & $\mathrm{H} 40$ & All strains \\
\hline Acridine orange & $\begin{array}{l}2 \cdot 9 \pm 1 \cdot 2 \\
\times 10^{3}\end{array}$ & $\begin{array}{l}8.7 \pm 7.5 \\
\times 10^{3}\end{array}$ & $\begin{array}{l}5 \cdot 7 \pm 5 \cdot 4 \\
\times 10^{2}\end{array}$ & $\begin{array}{l}4 \cdot 1 \pm 4 \cdot 2 \\
\times 10^{3}\end{array}$ \\
\hline India ink & $\begin{array}{l}1 \cdot 1 \pm 1 \cdot 0 \\
\times 10^{3}\end{array}$ & $\begin{array}{l}3 \cdot 5 \pm 2 \cdot 1 \\
\times 10^{2}\end{array}$ & $\begin{array}{l}5.7 \pm 5.4 \\
\times 10^{2}\end{array}$ & $\begin{array}{l}6.7 \pm 3.8 \\
\times 10^{2}\end{array}$ \\
\hline Latex agglutination & $\begin{array}{l}1.6 \pm 1.29 \\
\times 10^{4}\end{array}$ & $\begin{array}{l}1.8 \pm 1.9 \\
\times 10^{2}\end{array}$ & $\begin{array}{l}7.8 \pm 6.3 \\
\times 10^{2}\end{array}$ & $\begin{array}{l}3.2 \pm 4 \cdot 1 \\
\times 10^{2}\end{array}$ \\
\hline All methods & $\begin{array}{l}6 \cdot 7 \pm 8 \cdot 1 \\
\times 10^{3}\end{array}$ & $\begin{array}{l}3 \cdot 1 \pm 4.9 \\
\times 10^{3}\end{array}$ & $\begin{array}{l}6 \cdot 4 \pm 1 \cdot 2 \\
\times 10^{2}\end{array}$ & $\begin{array}{l}3.5 \pm 5 \cdot 4 \\
\times 10^{3}\end{array}$ \\
\hline
\end{tabular}

Each result is the mean of three observations. 
that fluorescent techniques are often more sensitive than direct microscopy," and for this reason the acridine orange method was of potential interest. However there was no apparent advantage to the acridine orange method, although the finding that none of the three methods was consistently superior suggests that it may be advisable to employ at least two of the methods in the routine immediate evaluation of CSF.

Sensitivity appeared to be related to capsular size; cells of $\mathrm{H} 40$, with the largest capsule, could be detected at a concentration of $6.4 \times 10^{2} \mathrm{CFU} / \mathrm{ml}$, while those of $\mathrm{H} 99$, the smallest, only at $6.7 \times 10^{3}$ $\mathrm{CFU} / \mathrm{ml}$. The latex agglutination test seemed to be particularly susceptible to this variable.

The number of organisms found in the CSF of patients with cryptococcal meningitis is not accurately known, but Perfect et $a l^{10}$ have described four patients with cryptococcaemia and meningitis who had pretreatment CSF counts of $10^{4}-10^{7} \mathrm{CFU} / \mathrm{ml}$. Although we used normal saline rather than CSF as the diluent, these figures are consistent with the findings reported here, since patients with cryptococcaemia generally have a larger burden of infection and are likely to fall into the group of $60 \%$ of patients whose CSF is positive on direct microscopy. The "cut off" at approximately $10^{3}$ organisms $/ \mathrm{ml}$ which we found provides a clear explanation for the negative microscopic findings in patients with less overwhelming infection.

These studies emphasise that all the methods currently available for the rapid diagnosis of cryptococcal meningitis have limitations in their ability to detect low grade infection. In some circumstances the latex agglutination test may be positive when microscopy is negative (perhaps due to "walling off" of the infection) $)^{3}$ but conversely, a negative antigen test does not exclude active infection." ${ }^{11}$ For these reasons, a combination of the latex agglutination test and one of the microscopic techniques appears to be the most satisfactory screening procedure for cryptococcal meningitis. Nevertheless, careful cultural techniques will remain the mainstay of the diagnosis of this infection.

I thank the Wellcome Trust and the Peel Trust for support; John McConnell for technical assistance and Avril Kirk for typing the manuscript.

\section{References}

' Hay RJ, MacKenzie DWR, Campbell CK, Philpot CM. Cryptococcosis in the United Kingdom and the Irish Republic: an analysis of 69 cases. $J$ Infect 1980;2: 13-22.

${ }^{2}$ Butler WT, Alling DW, Spickard A, Utz JP. Diagnostic and prognostic value of clinical and laboratory findings in cryptococcal meningitis. A follow-up study of forty patients. $N$ Engl J Med 1964;270:59-67.

${ }^{3}$ Goodman JS, Kaufman L, Koenig MG. Diagnosis of cryptococcal meningitis. Value of immunologic detection of cryptococca antigen. $N$ Engl J Med 1971;285:434-6.

: Grossgebauer K. Detection of Cryptococcus neoformans capsule using fluorescent, mucopolysaccharide-binding dyes. Klin Wochenschr 1980;58:943-5.

s Kwon-Chung KJ, Polacheck I, Bennett JE. Improved diagnostic medium for separation of Cryptococcus neoformans var neoformans (serotypes A and D) and Cryptococcus neoformans var gattii (serotypes B and C). J Clin Microbiol 1982; 15:535-7.

- Salkin IF, Hurd NJ. New medium for differentiation of Cryptococcus neoformans serotype pairs. J Clin Microbiol 1982; 15: 169-71.

' Kwon-Chung KJ. A new genus, Filobasidiella, the perfect state of Cryptococcus neoformans. Mycologia 1975;67:1197-200.

* Severance PJ, Kauffman CA. Diagnosis of cryptococcosis: comparison of various methods to detect Cryptococcus neoformans. Mykosen 1982;26:29-33.

${ }^{-}$Bennedsen J, Larsen SO. Examination for tubercle bacilli by fluorescence microscopy. Scand J Resp Dis 1966;47:114-20.

${ }^{10}$ Perfect JR, Durack DT, Gallis HA. Cryptococcemia. Medicine 1983;62:98-109.

"Gordon MA, Vedder DK. Serologic tests in the diagnosis and prognosis of cryptococcosis. JAMA 1966;197:961-7.

Requests for reprints to: Dr J Cohen, Wellcome Fellow in Infectious Diseases, Royal Postgraduate Medical School, Hammersmith Hospital, Du Cane Road, London W12 OHS, England. 